Cuadernos de Lingüística Hispánica $n^{\circ} .24$ ISSN 0121-053X • ISSN en línea 2346-1829 Julio-Diciembre 2014, pp. 6I-84

\title{
Las locuciones adjetivales en cinco diccionarios de la lengua española*
}

\author{
LUIS FERNANDO NIETO RUIZ" \\ lufer@uptc.edu.co
}

Recepción: 04 de marzo de 2014

Aprobación: 07 de mayo de 2014

Cómo citar este artículo: Nieto Ruiz, L. (2014). Las locuciones adjetivales en cinco diccionarios de la lengua española. Cuadernos de Lingüística Hispánica, 24, 61-84. Tunja: Uptc.

* Artículo de investigación científica. Contiene un avance de la tesis doctoral intitulada: "Estudio contrastivo en cinco diccionarios de lengua española". Es producto de una investigación detallada, rigurosa y exhaustiva sobre una parcela de la linguística como lo es la Fraseología.

* Licenciado en Idiomas Modernos, Magíster en Lingüística y candidato a Doctor en Filología Española. Profesor ocasional adscrito a la Escuela de Idiomas de la Universidad Pedagógica y Tecnológica. Profesor Catedrático de la Maestría en Linguística misma institución educativa. 


\title{
Resumen
}

Este artículo es un avance de la tesis doctoral intitulada "Estudio contrastivo en cinco diccionarios de lengua española". Este aporte investigativo es, ante todo, una reflexión en torno de los estudios léxicos que se han hecho hasta el momento en Colombia. A más de esto, se hace un recorrido teórico-epistemológico sobre tres temas importantes como la fraseología y su objeto de estudio: las unidades fraseológicas, las locuciones adjetivales; así como su manifestación en cinco diccionarios de la lengua española.

Palabras clave: fraseología, colocación, locución, Unidad fraseológica, locución adjetival.

\section{Adjectival phrases in five Spanish language dictionaries}

\begin{abstract}
This article is a preview of the doctoral thesis "Contrastive study in five Spanish language dictionaries". This investigative contribution is, above all, a reflection relating to lexical studies carried out in Colombia to date. Besides, it contains a theoretical and epistemological look at three important topics regarding phraseology and its object of study, including collocations and adjectival phrases; and its presence in five Spanish language dictionaries.
\end{abstract}

Key words: phraseology, collocation, locution, phraseological unit, adjectival phrase. 


\section{Les locutions adjectivales dans cinq dictionnaires de la langue espagnole}

\section{Résumé}

Cet article est un avancement de la thèse doctorale intitulée "Étude contrastive de cinq dictionnaire de langue espagnole". Cet apport de recherche est, avant tout, une réflexion autour des études lexicales qui ont été faites jusqu'à maintenant en Colombie. En plus, on fait un parcours théorique-épistémologique sur trois thèmes importants comme la phraséologie et son objet d'étude: les unités phraséologiques, les locutions adjectivales, ainsi que leur présence dans cinq dictionnaires de la langue espagnole.

Mots clés: phraséologie, collocation, locution, Unité phraséologique, locution adjectivale.

\section{As locuções adjetivais em cinco dicionários da língua espanhola}

\section{Resumo}

Este artigo é um avanço da tese doutoral intitulada "Estudo contrastivo em cinco dicionários da língua espanhola”. Este aporte de pesquisa é, ante tudo, uma reflexão em torno dos estudos léxicos que se tem realizado até o momento na Colômbia. Além disso, é feito um percurso teóricoepistemológico sobre três temas importantes como a fraseologia e seu objeto de estudo: as unidades fraseológicas, as locuções adjetivais; assim como sua manifestação em cinco dicionários da língua espanhola.

Palavras chave: fraseologia, colocação, locução, Unidade fraseológica, locução adjetival. 
"Desde el punto de vista lingüístico, toda expresión compuesta de sentido indivisible, tanto si se escribe formando una palabra como si se presenta articulada en dos o más, constituye una unidad léxica que ha de estudiarse y tratarse como tal".

Casares (1950, p. 169).

\section{Introducción}

La Fraseología se consolida como una disciplina lingüística que tiene por tarea central identificar determinadas palabras, e incluso grupos de estas, que con-forman expresiones con estructura, significado y sentido diverso, acorde con determinadas circunstancias comunicativas. Estas agrupaciones han dado matices interesantes; incluso, el hombre, desde sus inicios ya se sentía atraído por el uso de combinaciones estables de palabras, pues le servían como vehículo de su manifestación cultural.

Este trabajo investigativo se bifurca por el camino de las locuciones adjetivales que, de acuerdo con Corpas (1996, p. 88), son "una unidad fija del sistema de la lengua con los siguientes rasgos distintivos: fijación interna, unidad de significado y fijación externa. Estas unidades no constituyen enunciados completos por sí mismos; generalmente funcionan como elementos oracionales". Al respecto, el Diccionario de la Lengua Española la define como la "combinación fija de varios vocablos que funciona como una determinada clase de palabras" (2010, p. 1395). Lo anterior ratifica o confirma que este tipo de palabras tiene una jerarquía, dado que posee una hegemonía institucional representada en los niveles morfológico, sintáctico, semántico, fonológico y pragmático.

El objetivo central de este trabajo es identificar las locuciones adjetivales en los diccionarios de lengua española, a saber: (a) Diccionario de la Lengua Española, de la Real Academia Española (DLE) ${ }^{1}$; (b) Diccionario Panhispánico de Dudas, de la Real Academia Española (DPD) ${ }^{2}$; (c) Diccionario Fraseológico Documentado del EspañolActual (DFDEA) ${ }^{3}$, de Manuel Seco, Olimpia Andrés y Gabino Ramos; (d) Diccionario Fraseológico del Español Moderno (DFEM) ${ }^{4}$, de Fernando Varela y Hugo Kubarth y (e) Diccionario del Español Actual (DEA) ${ }^{5}$, de Manuel Seco, Olimpia Andrés y Gabino Ramos. El primer paso

\footnotetext{
Diccionario de la Lengua española, de la Real Academia Española.

Diccionario Panhispánico de Dudas, de la Real Academia Española.

Diccionario Fraseológico Documentado del Español Actual.

Diccionario Fraseológico del Español Moderno.

Diccionario del Español Actual.
} 
de la investigación fue la elaboración de un corpus linguiístico, en donde se recopiló los listados de locuciones adjetivales que se encontraron en los cinco diccionarios nombrados arriba.

Un segundo momento permitió realizar una fundamentación teórica sobre temas pertinentes a la investigación; por ejemplo, la fraseología, las locuciones, el adjetivo y el eje de este trabajo: las locuciones adjetivales. Posterior a esta introspección temática, se hace mención del método investigativo empleado y, por último, se presentan algunos resultados.

\section{Fundamentos teóricos}

\subsection{La Fraseología}

La Fraseología, subdisciplina de la Lexicología, aunque es poco investigada, sobre todo en nuestro país (Colombia) tiene como propósito principal el análisis de las unidades fraseológicas (UFs) provenientes, por lo general, de conversaciones coloquiales. Es común escuchar expresiones como: contra reloj, al rojo vivo, en ristre, de poca ropa, de tomay dame, alquilar balcón, de sangre caliente, entre muchas. Antes de profundizar en el tema es menester tener un concepto claro sobre lo que es y lo que en el fondo investiga la Fraseología. En el Diccionario de la Lengua Española (2001, p. 1086), se encuentra definida como 'un conjunto de frases hechas, locuciones figuradas, metáforas y comparaciones fijadas, modismos y mensajes existentes en una lengua, en el uso individual o en el de algún grupo'.

Al respecto, Seco (2009, p. XIII) dice que la Fraseología, en sentido propio, se relaciona con todas las "combinaciones de palabras que, en su práctica del idioma, no son formadas libremente por el hablante, sino que se le dan ya prefabricadas, como "paquetes" que tienen en la lengua un valor propio establecido por el uso tradicional". Ahora bien, Ruiz (1998, pp. 12-13) sostiene que la Fraseología se ocupa de las "unidades fraseológicas desde una concepción estrecha, fundamentalmente de las locuciones y frases proverbiales y, en un sentido más amplio, de refranes, dialogismos, aforismos, vocabulario técnico, fórmulas".

Las dos primeras definiciones tienen un elemento en común: la Fraseología se dedica básicamente a elementos lingüísticos ya existentes, que de acuerdo con Coseriu (1981, p. 113), se conocen como "discurso repetido", entendido como trozos de enunciados ya elaborados; entonces, la tarea del ser humano es utilizarlos. Pero desde un punto de vista más complejo se debe profundizar en su estudio, ya sea desde lo lingüístico evidenciando cada uno de sus constituyentes como pueden ser el aspecto sintáctico, semántico, fonético o, desde su intención comunicativa; es decir, qué se puede hacer y lograr con el uso de este recurso comunicativo. Hecho que conlleva la organización de la Fraseología gracias a su objeto de estudio: las unidades fraseológicas (UFS). Ahora bien, la tercera definición se centra en la organización y clasificación 
de dichas unidades. Al respecto, Corpas (1996, p. 51) propone tres grandes parcelas: "las colocaciones, las locuciones y los enunciados fraseológicos".

El primer apartado, las colocaciones, se refiere a la linealidad del signo planteada por Saussure, en este caso, las palabras utilizadas en el discurso; es decir, que es una asociación sintagmática conformada por unidades léxicas que presentan un orden en donde mínimo debe aparecer dos elementos léxicos. Veamos un ejemplo: hombre de armas tomar. En primer lugar, se manifiesta una linealidad; es decir, están presentes categorías gramaticales como: sustantivo + preposición + sustantivo + verbo; a más de esto, se evidencia una estructura gramatical de carácter preposicional: sustantivo + sintagma preposicional. Ahora bien, si vemos un poco más allá del aspecto puramente gramatical, la frase por sí sola no significa; por tanto, requiere de un elemento 'generador' de significado: Juan es un hombre de armas tomar, pues enfrentó a los delincuentes. El papel fundante de las colocaciones, entonces, consiste en identificar los elementos que constituyen la frase y la manera como están organizados.

Ahora, y como tercera parcela, están los enunciados fraseológicos. Valga la aclaración que para el segundo postulado (las locuciones), se presenta un capítulo aparte, pues es el eje de la investigación. Los enunciados fraseológicos han sido objeto de varias nominaciones: formulas de la vida social, frases habituales, fórmulas estereotipadas, oraciones rituales, fórmulas rutinarias. En este trabajo se toma como enunciado fraseológico. Entonces, se debe tener presente qué es un enunciado. Zuluaga, en Corpas (1996, p. 51), lo define como "una unidad de comunicación mínima de un acto de habla, que corresponde generalmente a una oración simple o compuesta, pero que también puede constar de un sintagma o una palabra". Para que se dé un enunciado fraseológico es menester que por sí mismo tenga una fuerza comunicativa clara y pertinente; es decir, que posea un significado concreto, completo e independiente; es un acto de habla autónomo, no depende de otros constituyentes, caso contrario de las colocaciones que pueden poseerlo o no, tal como se evidenció renglones arriba.

Las unidades fraseológicas tienen dos características fundamentales: son descriptivas y están conformadas por unidades de interacción social. En cuanto la primera, se encarga de representar la realidad mediante el uso de la palabra, ya sea oral o escrita. La naturaleza de los enunciados descriptivos permite evidenciar diversos procedimientos como metaforización, animación, analogía, entre otras, gracias al rompimiento de la linealidad del enunciado fraseológico. Ahora bien, esto no tendría razón de ser si no tuviese eco; es decir, si no se pusiera en, para, con la sociedad, y esta es la segunda característica, el factor social de los enunciados fraseológicos puestos en escena mediante la interacción comunicativa; dicha actividad es producto de la lengua hablada almacenada en muestras 
representativas de conversaciones y diálogos sostenidos entre la población, independientemente de las clases sociales, géneros; así como los niveles de instrucción a que pertenezca. Muestras evidentes de enunciados fraseológicos son las paremias, los proverbios, los dichos, los refranes, las coplas populares. Algunos ejemplos de estos son: encontrarle la horma al zapato; hacer castillos en el aire; una sola abeja no puede hacer miel; con perdón; muchas gracias; de nada; por nada; hasta pronto; tanto va el cántaro al agua basta que por fin se rompe; hacerse el de la oreja gocha; caballo que bien anda, cualquiera lo manda; gallina vieja bace buen caldo; cuando el gato no está, los ratones hacen fiesta; el cobarde es león en su casa y liebre en la plaza; el que remienda no estrena, entre muchas.

1.1.1 Las locuciones. En renglones supra se mencionó que esta parcela era tema aparte; por tanto, aquí se retoma este apartado. Casares (1950, p. 167) es uno de los pioneros en el tema de la locución; la define como "el conjunto de dos o más palabras que no forman oración perfecta o cabal" y más adelante aclara que se refiere a un "conjunto de voces vinculadas de un modo estable y con un sentido unitario" (p. 168). Lo anterior confirma que cualquier grupo de palabras no forman una locución. Estas requieren de ciertas características que más adelante se evidenciarán.

Continuando con la definición de locución, Corpas (1996, p. 88) dice que son "unidades fijas del sistema de la lengua con los siguientes rasgos distintivos: fijación y unidad de significado. Estas unidades no constituyen enunciados completos, y, generalmente, funcionan como elementos oracionales". El primer rasgo designa la manera como se integra una expresión del discurso dentro del sistema de la lengua, desde el punto de vista formal, con los diferentes elementos lingüísticos que constituyen la locución. Ahora bien, la fijación está directamente relacionada con la técnica del discurso que comprende las unidades del vocabulario de dicha lengua, articulada a diferentes reglas necesarias para su combinación en el hablar; por tanto, se constituyen intrínsecamente en lenguaje repetido -expresiones fijas-, debido a su uso permanente, pues generan unidades formadas por dos o más palabras invariables; por ejemplo: en ascuas, por arte de magia, sin ton ni son; mas no ascuas en, magia de por arte, sin son ni ton.

Zuluaga, en Martínez (1996, p. 19), plantea cuatro rasgos característicos de la fijación, a saber:

1. La inalterabilidad del orden de los componentes. Ejemplo, Calentársele la sangre, mas no la sangre calentársele.

2. Invariabilidad de alguna categoría gramatical. Es correcta la locución Luna de miel, pero no Lunas de miel, lunas de mieles, luna de mieles. Luego las categorías gramaticales deben prevalecer en las unidades fraseológicas. 
3. Inmodificabilidad del inventario de sus constituyentes. Aunque guarda cierta relación con la anterior, tiende a diferenciarse en la no aceptación de supresión 0 adicionamiento de constituyentes gramaticales. La locución Hay moros en la costa no acepta alteraciones como: Hay un moro en la costa, hay varios moros en la costa.

4. Insustituibilidad de los elementos que constituyen la locución. Ojos que no ven, corazón que no siente. Pero no: Oídos que no escuchan, corazón que no siente.

La idiomaticidad, de acuerdo con Ruiz (1997, p. 12), es «una propiedad mediante la cual el significado de la estructura no puede deducirse del significado de sus partes tomadas por separado o en conjunto». Esto permite traer a colación la semántica, en tanto que las locuciones tienen como rasgo característico el significado traslaticio o idiomático de, al menos, uno de sus componentes. Entonces, una locución es el producto de una permutación semántica en donde aparecen dos eventos importantes: la denotación y la connotación. El primero, el significado conceptual (denotativo) posee una organización que articula tres ejes fundantes de la lingüística: sintaxis, fonología y semántica. Luego la denotación demuestra la proporción de símbolos abstractos que intervienen en la interpretación de una locución, de tal forma que dicha configuración sea representativa; es decir, que muestre con exactitud lo que se requiere saber para poder diferenciar un significado de otro.

Ahora bien, la connotación hace alusión a la significación; es decir, aquel conjunto de valores agregados a los rasgos denotativos de un concepto, para el caso que nos ocupa, de una locución, los cuales están directamente ligados a ciertos rasgos característicos del referente. Desde el punto de vista de la lógica, la connotación se relaciona con la comprensión, definida como un conjunto de relaciones que se generan entre una expresión lingüística y diversos recursos extralingüísticos. Esto quiere decir que un referente puede estar constituido por diversas características, ya sean físicas, psicológicas, sociales, culturales, ideológicas; entonces, la tarea de la connotación es englobar las diversas propiedades del referente, ya sean de carácter positivo o negativo. Si bien es cierto que la connotación puede variar de una comunidad lingïística a otra, también debe tenerse presente que las locuciones deben mantener un significado general, pues esto es lo que caracteriza las expresiones fijas de la lengua.

1.1.1.1 Características de las locuciones. Dentro de las principales características de las locuciones se puede nombrar las siguientes:

1. Fijación normal y psicolingüística.

2. Son elementos prototípicos de la Fraseología.

3. No funcionan de forma independiente ni aislada del contexto. 
4. Su significado depende de la función sintáctica que se realiza en la conversación; de acuerdo con dicha función, depende su clasificación.

5. Las propiedades distintivas de las locuciones son su institucionalización, su estabilidad sintáctico-semántica y su función denominativa.

6. El grado de fijación, con respecto a las unidades fraseológicas es mayor, pues forman parte del sistema de la lengua y funcionan como elementos sintácticos dentro de las oraciones.

\subsection{El adjetivo}

La investigación requirió de la elaboración de un estado del arte sobre constructos teóricos relacionados con el adjetivo. Se acudió a autores como: Samuel Gili Gaya, Marta Lujan, Bernard Potier, Emilio Alarcos Llorad, Francisco Osuna García, entre otros. Como representación de esta categoría gramatical, se optó por trabajar los postulados propuestos por Violeta Demonte e Ignacio Bosque (1999). Para ellos el adjetivo es:

Una categoría gramatical cuyos miembros tienen unas características muy precisas;

y es también una categoría semántica: hay un tipo de significado que se expresa preferentemente por medio de adjetivos. Como categoría gramatical puede ser un atributo o modificador del nombre sustantivo; unido a él, y a sus determinantes y cuantificadores, forma una frase nominal en la cual ha de concordar en género y número con el nombre modificado (p. 133).

Baste recordar que la Gramática, en sentido general, se dedica al estudio sistemático del lenguaje mediante una serie de categorías que se enlazan y, en sentido estricto, tiene que ver con las formas fundamentales de una lengua y su respectivo contenido significado que resulta de la respectiva combinación de dichas categorías. La Nueva Gramática de la lengua Española (2010, p. 3) la define como "una disciplina combinatoria centrada fundamentalmente en la construcción interna de los mensajes y en el sistema que permite crearlos e interpretarlos". Para que dicha construcción se dé se requiere de las unidades sintácticas, también conocidas como categorías gramaticales (artículo, sustantivo, adjetivo, verbo, adverbio, pronombre, preposición, conjunción e interjección). Al respecto, es pertinente decir que dichas unidades pueden combinarse y formar unidades mayores, dando lugar a los llamados grupos sintácticos: nominal, adjetival, verbal, adverbial, pronominal, preposicional, conjuntivo e interjectivo. Las anteriores combinaciones o categorías generan diferentes estructuras sintácticas, dentro de estas las locuciones, objeto de esta investigación $\mathrm{y}$, en forma concreta, las adjetivales.

1.2.1 Clasificación del adjetivo. Demonte y Bosque (1999, p. 133) presentan una clasificación léxico-semántica del adjetivo en tres grandes parcelas, a saber: (a) 
relacionales, (b) calificativos y (c) adverbiales. A continuación se hace una explicación breve de cada una de estas clases:

1.2.1.1 Adjetivos relacionales. Asignan diversas propiedades al objeto modificado, dando lugar a relaciones semánticas muy complejas y diversificadoras, debido al objeto de modificación y su relación con las articulaciones externas a él, lo cual permite afirmar que se establece una cualidad extrínseca que puede estar relacionada con tiempo, espacio, clase, materia, propiedad, procedencia, situación, pertenencia, nacionalidad, entre muchas. Esta clase de adjetivos mantiene una relación directa frente al sustantivo referido y, por lo general, se derivan del mismo sustantivo: policía > policial; sindicato > sindical; gobierno $>$ gubernamental. Los adjetivos relacionales tienen características particulares que los hacen bastante diferentes de los calificativos; dentro de las más relevantes se pueden nombrar las siguientes:

1. Expresan varias propiedades.

2. Nunca actúan como predicados.

3. Nunca van antepuestos.

4. No pueden ser base de los adverbios terminados en -mente.

5. No admiten modificadores adverbiales.

6. No permiten gradación ni intensificación.

7. No se relacionan o coordinan con el adjetivo calificativo.

8. Varios adjetivos relacionales no pueden encontrarse en posiciones predicativas.

9. Los adjetivos relacionales no aceptan adverbios de grado ni pueden formar parte de construcciones comparativas.

1.2.1.1.1 Clases de adjetivos relacionales. Demonte y Bosque (1999, pp. 162-65) proponen tres grandes parcelas de esta clase de adjetivos:

1. Adjetivo relacional correspondiente a una función gramatical. Este adquiere un valor semántico que corresponde a una función gramatical canónica; dichos valores únicamente se dan cuando el nombre modificado es una nominalización: Feria nacional > feria de la nación; novela caballeresca > novela de caballería; ideas republicanas > ideas de la república.

2. Adjetivo relacional correspondiente a una función semántica adjunta. El adjetivo, entre una serie de valores semánticos adjuntos, adopta solo uno. Puede ser: locativo, instrumental, causal, final, posesivo, etc. Vista aérea > vista desde el aire; energía eólica > energía producida por el viento. 
3. Adjetivo relacional de significado en el nombre. Este significado corresponde a la relación parte-todo, continente-contenido, forma-fondo u otras similares que, en ocasiones, se asocia a la preposición «de», en construcciones como: cuadro de mármol, pase de cortesía, estrella de mar, prestigio cultural, educación primaria.

1.2.1.2 Adjetivos calificativos. Estos, a diferencia de los relacionales, asignan una propiedad que puede ser estable o transitoria. Si bien, en esta clase de adjetivos se evidencia la forma primitiva, no es de descartar la derivada de formas verbales como las terminaciones infijas en: -dor/-tor: acosador, impostor; -ante: ignorante; -oso: celoso; udo: cornudo; -ble: endeble. De igual manera, son generadores de cualidades particulares, dado que indican rasgos distintivos de un objeto con otro: lápiz largo, frente a lápiz corto, propiedades que permiten una mejor identificación.

1.2.1.2.1 Características de los adjetivos calificativos. Grosso modo, se puede nombrar las siguientes:

1. Los adjetivos calificativos son de polaridad y gradualidad.

2. Algunos adjetivos calificativos presentan oposiciones de polaridad; por tanto, forman pares, representando grados extremos de determinadas cualidades o características (gordo/flaco; corto/largo; claro/oscuro [...]

3. La gradualidad se puede manifestar de varias maneras: en primera instancia, la probabilidad de llevar adverbios de intensificación; en segunda medida, el hecho de poder constituir construcciones comparativas y, en tercer lugar, permiten la combinación adverbial en una forma diversa: extremadamente útil, demasiado pesado, exageradamente gordo.

4. La relación entre el sustantivo y el adjetivo calificativo, semánticamente, genera una conjunción; por tanto, da lugar a dos proposiciones. Ej. Carro rojo. Las designaciones son: ser un carro y poseer un color.

1.2.1.2.2 Clasificación de los adjetivos calificativos. Es bien sabido que hay diversidad de clasificaciones relacionadas con el adjetivo. Sin embargo, estos se pueden clasificar con base en ciertos niveles lingüísticos de orden sintáctico, morfológico y semántico. Ahora bien, Demonte y Bosque (1999) los clasifican de acuerdo con el criterio léxico semántico de la siguiente manera:

1. Adjetivos de dimensión. Estos se refieren a longitudes espaciales de los objetos físicos: largo/alto/ ancho; así como a su volumen. Así, se generan adjetivos como: largo, ancho, estrecho, profundo, alargado, estirado, ensanchado; como se puede evidenciar, esta dimensión permite la elaboración de grupos adjetivales. 
2. Adjetivos de velocidad. Lerdo, lento, rápido. Algunos de estos adjetivos pueden ser empleados como adjetivos adverbiales: apresuramiento sigiloso, fugaz mirada, sonrisa momentánea. Estos adjetivos pueden ir ante o pospuestos.

3. Adjetivos de propiedad física. Se refieren a objetos perceptibles mediante los sentidos. Estos (adjetivos) se subdividen en grupos concretos que, a su vez, se diferencian de los de dimensión y de velocidad, de acuerdo con características concretas como: la forma: redondo cuadrado, cóncavo; el peso: suave, ligero, liviano macizo; el sabor: agrio, amargo, acido; el tacto: liso, blando, duro; el olor: maloliente, fétido, repugnante; la temperatura: helado, frío, cálido y la sonoridad: ronco, fuerte débil, grave.

4. Adjetivos de color. Esta clase presenta cinco grandes ramificaciones: (a) los colores genéricos: blanco, rojo, amarillo, negro; (b) los derivados de los colores: azulado, verdoso, morado, rojizo; (c) los compuestos: rojiblanco, blanquinegro; (d) los sustantivos especializados relacionados con los colores: salmón, mostaza, naranja y (e) los compuestos sintagmáticos formados por un adjetivo relacionado con el color básico seguido de un sustantivo distinguidor o un adjetivo que indica matiz: verde oliva, verde botella, verde pistacho, amarillo pollito, rojo grana [...]

5. Adjetivos de edad. Esta clase se aplica tanto a seres animados como no animados: moderno, joven, viejo, nuevo, anciano, añejo antediluviano.

6. Adjetivos de evaluación o valorativos. Hermoso, bello bonito, agradable, excelente, maravilloso, pésimo y tremendo son algunos ejemplos de esta clase de adjetivos.

7. Adjetivos de aptitudes y predisposiciones humanas. Pueden indicar tanto actitudes intelectuales: inteligente, despierto astuto, como emocionales: cariñoso, arrogante, petulante. También pueden evocar pasiones y disposiciones humanas: agresivo, nervioso, autoritario, envidioso.

1.2.1.3 Adjetivos adverbiales. En primer lugar, es menester aclarar el paralelismo que reina entre el adjetivo y el adverbio. Carbonero (1978, p. 189) señala que "adjetivo y adverbio son categorías adnucleares, es decir, las dos inciden sobre el núcleo de su respectivo sintagma”. Dicho con otras palabras, el adjetivo se manifiesta como un incidente nominal y término marcado; en tanto que, el adverbio es incidente verbal y término no marcado, puesto que también, incide sobre otros elementos. Lo anterior permite concluir que el adjetivo y el adverbio tienen la función común de términos adyacentes en sus correspondientes sintagmas. Razón tiene Gutiérrez (1978, p. 212) cuando afirma que "los adverbios se relacionan con el verbo de forma análoga que el adjetivo con el nombre hasta tal punto que al adverbio se le ha llamado alguna vez adjetivo verbal". 
Para el caso de las nominalizaciones deverbales, en tanto construcciones lingüísticas caracterizadas por la presencia de los sustantivos que adquieren determinadas estructuras sobre los respectivos verbos que los modifican, en cuanto al comportamiento sintáctico y semántico se refiere; dicho proceso manifiesta una productividad de los procedimientos de derivación de nombres, mediante ciertas bases verbales y sus articulaciones entre construcciones oracionales y nominales. Lo anterior permite observar que cuando en el sintagma verbal se utilizan adverbios terminados en "mente", estos se pueden fusionar, en la nominalización, como adjetivos. A manera de ejemplo: Contestó el examen rápidamente > contestación rápida al examen.

1.2.1.3.1 Clasificación de los adjetivos adverbiales. Continuando con Demonte y Bosque (1999, p.204), estos adjetivos se pueden organizar en dos grandes ramas, a saber: (a) adjetivos adverbiales intensionales y (b) los adverbiales eventivos 0 circunstanciales. Los primeros modifican a la intensión, mas no el objeto designado por el sustantivo. Ahora bien, mientras los adjetivos calificativos designan propiedades, los adjetivos intensionales las modifican. En cuanto a los segundos se refiere, es decir, los eventivos, estos no hacen alusión a los objetos constitutivos; por el contrario, se dedican a los objetos o procesos en cuanto a entidades que tienen lugar y, por tanto, suceden en un tiempo y en un espacio determinado. A guisa de ejemplo, al hablar de las frecuentes confrontaciones de saberes, no se hace referencia a la forma particular de la evaluación, sino al hecho de que dicho acontecimiento se lleva a cabo con una determinada periodicidad; dicho con otros términos, se manifiesta una estructura temporal, en este caso, estable.

\subsection{Locuciones adjetivas}

Antes de profundizar sobre las locuciones adjetivales es menester decir que uno de los componentes fundamentales para su estudio es el sintagma, definido por Roca Pons (1970, p. 118) como "toda sucesión de elementos significativos, sean o no palabras". Ciertamente, los sintagmas manifiestan ideas, tanto de coordinación como de subordinación de las diferentes categorías gramaticales que pueden articularse dentro del grupo que conforme; por ejemplo, las diversas relaciones entre el sujeto y el predicado; así como los complementos y las proposiciones subordinadas que constituyen la oración.

Respecto de los sintagmas, Bally, Ch. en Roca Pons (1970, p. 121) resalta "el carácter binario”. Lo anterior evidencia, como mínimo dos grandes relaciones sintagmáticas en la oración sintagma nominal y sintagma verbal. Al interior de estos (y en consonancia con las categorías gramaticales) se encuentran binomios sintagmáticos: adjetival, adverbial, preposicional, conjuntivo e interjectivo.

Ya hecha la aclaración anterior sobre el sintagma, en este artículo se tomó como referente la clasificación propuesta por García-page (2000, pp. 115-119), quien propone 
tres grandes grupos de locuciones adjetivas, a saber: (a) sintagma adjetival, (b) sintagma preposicional y (c) el binomio coordinativo. La primera parcela agrupa los siguientes sintagmas: adjetivo + sintagma preposicional; adjetivo + adverbio o adverbio + adjetivo; estructura comparativa: adverbio + adjetivo + comparación o adjetivo + adverbio + comparación. En el segundo grupo se clasifican los siguientes sintagmas: preposición + nombre (tanto en singular como en plural); preposición + artículo + nombre; preposición + nombre + artículo; preposición + adjetivo + nombre; preposición + cuantificador + nombre; preposición + artículo + nombre + sintagma preposicional; preposición + nombre + adverbio; preposición + nombre + conjunción + nombre; preposición + artículo + nombre + conjunción + preposición + artículo + nombre $;$ de + verbo + conjunción + verbo. Y en el tercer apartado se encuentra la estructura: adjetivo + conjunción + adjetivo.

\section{Sobre la metodología}

El trabajo se apoyó en la investigación descriptiva, que de acuerdo con Dunkhe en Camacho (2008, p. 71) este tipo de investigación "busca interpretar algo que se encuentra representado a través de datos específicos sobre las propiedades de personas, grupos, comunidades o cualquier otro fenómeno sometido a análisis". Este tipo de investigación se funda en las ciencias sociales y del conocimiento y busca, tanto probar teorías, leyes científicas, principios básicos, como establecer relaciones entre fenómenos y generalizaciones analíticas. Su fin primordial se asocia con principios del conocimiento científico y con el mejoramiento de los procesos y metodologías investigativas.

El referente o fuente de información de este trabajo fue cinco diccionarios de la lengua española. Estos son: (a) Diccionario de la Lengua Española, (b) Diccionario Panhispánico de dudas, (c) Diccionario Fraseológico Documentado del Español Actual, (d) Diccionario Fraseológico del Español Modernoy (e) Diccionario del Español Actual. En cuanto al primer diccionario se refiere, se trabajó la vigésima segunda edición corregida en el año de 2009, impreso en México por Espasa Calpe; esta es una obra en permanente actualización, gracias a la creación, por parte de la Academia, del Banco de datos del Español, el Corpus diacrónico del Español (CORDE) y el Corpus de Referencia del Español Actual (CREA); la actualización lexicográfica es asumida por las veintiuna academias mundialmente reconocidas; en este se encuentran más de 270 millones de registros léxicos, lo cual evidencia su riqueza patrimonial.

El Diccionario Panhispánico de Dudas corresponde al año 2005, fue publicado en Madrid por Santillana. Las comunicaciones, a nivel mundial, permitieron que la Academia de la Lengua Española pusiera al servicio de la comunidad este diccionario, cuyo léxico sirve de instrumento para resolver diversas dudas que asaltan a los hablantes en cuanto al 
manejo del idioma e, incluso, para aquellas personas que desean mejorar el conocimiento de la lengua española. Bien es sabido que la lengua está en cambio permanente en el transcurso de la historia; este diccionario evidencia la existencia de diversos cambios lingüísticos manifiestos en los niveles fonético, morfológico, sintáctico y semántico, teniendo siempre presente las respectivas normas vigentes del español actual.

Manuel Seco, Olimpia Andrés y Gabino Ramos, en el año de 2009, ponen a disposición la cuarta reimpresión del Diccionario Fraseológico Documentado del Español Actual, publicado en Madrid por la Editorial Aguilar. En este se informa, de manera amplia, sobre la parcela interesante del léxico español conocida como las unidades fraseológicas, cuyos componentes son palabras, de hecho ilimitadas, que cumplen diversas funciones gramaticales y cuya articulación genera diversidad de variantes que, en ciertas ocasiones, alcanzan algún grado de fijeza, razón por la cual toma importancia este diccionario al prestar atención necesaria a este tipo de manifestaciones del lenguaje.

Fernando Varela y Hugo Kubarth son los autores del Diccionario Fraseológico del Español Moderno, publicado en el año de 1994, por la Editorial Gredos de la ciudad de Madrid. Este diccionario tiene mucho en común con el nombrado en el párrafo inmediatamente anterior, en tanto que tiene un eje transversal: la unidad fraseológica. El diccionario, además de ofrecer un orden sobre los elementos que constituyen los fraseologismos, permite ver la estabilidad de los elementos que los constituyen, característica fundamental de las unidades fraseológicas. A manera de ejemplo, en la locución tomar del pelo, debe tener firmeza en cada uno de los elementos o palabras que la componen y, de hecho, debe prescindir de derivaciones como tomadura del pelo, el pelo ha sido tomado [...] Lo anterior permite decir que el diccionario presenta una organización estructural de las locuciones; así como su manifestación léxico-semántica.

Como última fuente de consulta está el Diccionario del Español Actual de Manuel Seco, Olimpia Andrés y Gabino Ramos, publicado en el año de 1999, en Madrid, por el Grupo Editorial Aguilar. Una característica fundamental de este diccionario es que toma su catálogo léxico a partir de realidades comprobadas del uso de la lengua, que proceden, en su mayoría, de la lengua escrita como documentos literarios, tanto de carácter didáctico como práctico; hecho que permite garantizar y comprobar la realidad de los diversos usos de esta lengua en particular, cosa imposible de evidenciar en los enunciados hablados. Otro hecho relevante de este diccionario es que tiene presente la cronología de las palabras, pues su recorrido a través del tiempo evidencia estabilidad necesaria para otorgar credibilidad a determinadas unidades léxicas.

La consulta permanente en los diccionarios nombrados anteriormente requirió la profundización en la Linguística del Corpus. Como resultado de esta exploración se planteó 
una ruta de trabajo bajo los siguientes aspectos: (a) la selección de un modelo lingüístico, para el caso, basado en las tres clases de locuciones adjetivales anunciadas párrafos supra; (b) la aplicación de dicho modelo a la información compilada y (c) la sistematización de la información. Para el logro de lo anterior, se elaboró un corpus linguiístico, entendido, de acuerdo con Baquero (2010, p. 28) como "una muestra de gran cantidad de documentos almacenados en algún medio electromagnético u óptico, para permitir la automatización de tareas como la búsqueda y recuperación de información, cálculos de referencias y clasificación de los datos".

El corpus elaborado respondió a determinados principios básicos, como: (a) representatividad, (b) estandarización y (c) tipología textual. En cuanto al primer criterio, tiene presente tanto elementos internos relacionados con las categorías lingüísticas (relaciones sintagmáticas: adjetivales y preposicionales) como externos (tipo, género, modalidad, origen y finalidad de los textos); es decir, este aspecto se relaciona con elementos extralingüísticos. El segundo constituyente responde al ajuste a un patrón común de términos para que se puedan utilizar como modelo de recolección de información y, en el tercer aspecto, se tomó como referencia muestras de lengua escrita que aportan datos relevantes para la descripción de elementos particulares de la lengua como las locuciones adjetivales; esta característica permite hablar de un corpus especializado, dado que se encarga de compilar exclusivamente locuciones adjetivales.

\section{Sobre el corpus de la investigación}

El corpus lingüístico sobre las locuciones adjetivales en los cinco diccionarios, nombrados párrafos arriba, permitió profundizar y establecer tres grandes paradigmas locucionales. El primer momento condujo a la identificación de semejanza o correlación de grupos sintagmáticos. En segunda instancia, se profundizó en la relación de contraste por diferencias y, por tanto, características propias de cada diccionario en lo concerniente al manejo de las locuciones adjetivales. Y la tercera fase condujo al análisis lingüístico de las locuciones; hecho que permitió evidenciar el manejo de diferentes categorías y estructuras gramaticales propias de la lengua española. Debido a la extensión del análisis, en este artículo se hace una breve sinapsis del primer apartado, mediante la puesta en escena de los aspectos sintagmáticos más relevantes.

El primer aspecto es la presencia del sintagma adjetival. Luego de hacer una revisión, se comprobó que el Diccionario de la Lengua española (DLE) evidencia un número representativo de locuciones sintagmáticas adjetivales de estructura Adj. + SP. Algunos ejemplos son: corto de manos, blando de corazón, libre de polvo y paja, largo de lengua, duro de oído, flaco de memoria, fuera de serie [...] Los demás diccionarios, escasamente evidencian uno que otro ejemplo. (DFDEA) becho un cristo, becho una 
facha, subido de color. El (DFEM) salida de tono, hecha las cachas. El (DEA) picado de la tarántula. El (DPD) no trae ejemplo alguno.

Un segundo aspecto por resaltar, en locuciones adjetivales es la presencia del sintagma preposicional. Al respecto, es pertinente tener claro que, La Nueva Gramática (2010, p.557) define la preposición como "palabras invariables y casi siempre átonas que se caracterizan por introducir un complemento [...] que se denomina término". En la locución al por mayor, el término de la preposición al es por mayor. Valga la aclaración, dado que dicho término puede ser un grupo nominal, adjetival y preposicional. Luego es pertinente afirmar que la preposición se puede unir a una palabra o grupo de palabras con las que forma construcciones preposicionales, cuya tarea es complementar, ya sea a un sustantivo, verbo, adjetivo, adverbio o pronombre. Veamos algunos ejemplos sobre lo dicho: a barbeta, a distancia, de buenas, de bigotes, a demonios, de capona, de chichinabo, de baja, de compromiso, en barbecho, a granel, a mano, al por mayor, a primera sangre, con todos los sacramentos, de todos los diablos, ajeno de verdad, corto de vista, limpio de polvo y paja, entre varios.

Respecto del sintagma preposicional de la estructura $\mathrm{P}+\mathrm{N}$., el DEL presenta ejemplos como: a granel, a muerte, a surco, de compromiso, de hierro, de ley, de turno, de vientre, en serie, del corazón, en suspensión, de bandera, a mano, a turno, de barrio, a chorro, con gancho, en masa, de estómago, sin sombra, a barbeta, de abrigo. En el DFDEA se encuentra muestras como: a dedo, de letras, a brazo, de imitación, de fiesta, en presencia, de dios, de aluvión, de base, a sangre y fuego de cartón, de goma, de bierro, de miel. En el DFEM se encontró estos ejemplos: de balde, a barullo, de bolsillo, por cabeza, de cojones, a conciencia, ni cristo, de culo, al dedillo, sin duda, de marras, por pelotas, al aire, por arrobas. El DEA presenta algunos ejemplos como: de agua, de alcoba, de armas, de baño, de bulto, de cajón, de cámara, de cine, de conejo, de nieve, de palo, de pila, depito, de pueblo, para escritorio. La preposición es poco utilizada en las locuciones adjetivales que muestra el DPD; algunas muestras son: en color, de presión, de perogrullo, de balde.

Otra estructura sintagmática preposicional es: $\mathrm{P}+\mathrm{A}+\mathrm{N}$. El DLE presenta una muestra representativa de esta clase de locuciones. Algunas muestras son: a la holandés, a la marquesota, a la orden, a la birulé, de las narices, de la bostia, del carajo, de los demonios, del oeste, hasta el tope, por un tubo, hasta las narices, por el estilo. En el DEA encontramos algunos ejemplos: del asa, a la baja, a la brasa, de la broma, del copón, a la espalda, de la estampita, del evangelio, de la incumbencia, del infierno, de la lanza, del membrillo, del milló. En cuanto al DFDEA se puede mencionar las siguientes muestras: a la antigua, a los alcances, del avestruz, del ala, del año, a la baja, a la carta, al lomo, de los cojones, del corazón, a la funerala, de a folio, a lo gato, de la mano, de los 
nervios, de las pelotas, de la tierra, entre otros. El DFEM presenta pocos ejemplos de esta estructura: en un avemaría, a la carrera. En el DPD no se encontró esta clase de locuciones adjetivales.

En algunos ejemplos nombrados en el párrafo anterior se encuentra la preposición acompañada de un artículo y seguida de un nombre o un adjetivo. A la orden, de la hostia, hasta la bandera, por un tubo, de los diablos. Es de resaltar el fenómeno gramatical y, por tanto, fonológico de la supresión de un elemento lingüístico, en este caso la vocal con que acaba una palabra cuando la que le precede comienza por otra vocal, cabe aclarar que esto se da únicamente con el artículo en singular y para el género masculino: de el > del oeste, de el día > del día, a el vacío > al vacío, etc. Es evidente señalar que dicha elisión sólo se da con la preposición "de".

Otra estructura es $\mathrm{P}+\mathrm{N}+$ Adj. Algunas muestras que presenta el DLE son: a dinero seco, a palo seco, de marca mayor, de sangre calientelfría, en folio mayor/menor, de sentido común. El DEA sólo evidencia este caso: de puertas abiertas. El DFEA presenta las siguientes muestras: al aire libre, de agua dulce, a brazo partido, de bata blanca, de brocha gorda, a carta cabal, a cielo abierto, a cuerpo limpio, de clavo pasado, de cordero degollado, de cuerpo entero, en carne viva, de género tonto, a puerta cerradal abierta, de perro apaleado, de ternero degollado, de tierra adentro. El DFEM presenta locuciones como: a brazo partido, a carta cabal, la mano tonta, a pecho descubierto, a sangre fría. El DPD acude al latín y presenta esta evidencia in articulo mortis.

Y como tercer elemento de análisis está el binomio adjetivo + conjunción + adjetivo . De esta estructura son muy pocas las muestras encontradas. El DLE presenta estos ejemplos: $d e$ fuera a fuera, sano y salvo, hecho y derecho, de oro y azul. En el DFEA: en blanco y negro, constante y sonante, cormudo y apaleado, corriente y moliente. Es pertinente comentar que estos son los únicos dos diccionarios que presentaron esta clase de locuciones adjetivales.

\section{Análisis de la información}

Esta reflexión parte de dos fundamentos teóricos básicos de la investigación: primero, las clases de adjetivos que aparecen en las locuciones adjetivales; segundo, los elementos gramaticales que intervienen en la construcción de las locuciones adjetivales.

En primer lugar, con base en la clasificación hecha por Demonte y Bosque (1999, p. 133), es menester aclarar que los adjetivos calificativos son los más utilizados en las locuciones adjetivales, dado que designan cualidades, que pueden ser constatables objetivamente gracias a determinados elementos característicos como color, forma, calidad, aspecto físico e, incluso, determinadas relaciones situacionales y temporales. Dentro de las clases de adjetivos, se puede nombrar las siguientes: 
1. De dimensión. Adjetivos como corto y largo son generadores de locuciones adjetivas como: Corto/largo de manos. Las longitudes espaciales a que aluden estas locuciones, a más de manifestar ideas opuestas o contrarias, generan la antonimia. Grande/ pequeño, alto/bajo, blanco/negro, rápido lento, entre otros ejemplos. Sin embargo, la oposición va mucho más allá. La primera locución corto de manos, se refiere a aquella persona que carece de conocimientos mínimos para desempeñar determinado trabajo; por tanto, la antonimia largo de manos, se relacionaría con aquella persona que posee grandes saberes para realizar determinada tarea o trabajo; pero, la realidad es otra, pues la locución largo de manos, se refiere a quien se dedica al hurto. Analicemos otro ejemplo: largo de lengua, se utiliza para nombrar a aquel ser humano que es demasiado imprudente con su manera de hablar. La antonimia se daría con la locución corto de lengua, que vendría a ser quien es prudente cuando se expresa, pero no es así, esta se refiere a quien es muy tímido para hablar.

La locución Corto de vista alude a una persona que posee determinado defecto en alguno de sus ojos; sin embargo, el sentido que adquiere esta locución se relaciona con aquella persona que no quiere ver lo que está sucediendo a su alrededor y que no tiene espíritu de superación, siempre está a la espera de que los demás hagan todo por él o ella.

Es de anotar que si se da la antonimia, también se genera la sinonimia. Al respecto, Lyons (1991, p. 56) plantea dos clases: parcial y absoluta. Se puede decir, que en las locuciones adjetivales se encuentra la primera. Tomemos las locuciones largo de uñas y largo de manos. Las dos se refieren a aquellas personas que les gusta vivir de lo ajeno, es decir, es un apelativo para el ladrón.

2. De velocidad. Estos adjetivos contribuyen a formar locuciones como: Ligero de cascos, a lo loco, a toda mecha (A toda velocidad); A todo meter (A máxima velocidad); en dos paletadas (en un instante); Palmo a palmo (Con gran lentitud o grandes dificultades); a toda pastilla (a toda velocidad, a toda potencia, a todo volumen); de prisa y corriendo (Con precipitación, atropelladamente).

3. Ahora, veamos los adjetivos calificativos de propiedad física. Blando de corazón hace alusión a una persona que se compadece de todo; a quien es algo sordo se le conoce como duro de oído; flaco de memoria es un ser olvidadizo, de memoria poco firme. De bierro es algo o alguien muy fuerte, resistente y firme.

4. De color. Aunque son pocos los ejemplos se pueden mencionar los siguientes: Noche en blanco (noche en que no se puede dormir); a la luz del día (sin ocultar nada, de forma no clandestina); azul de mar (azul de matiz más oscuro, parecido al que suelen tener las aguas del mar). 
5. Los adjetivos de edad son utilizados, ya sea para referirse a las personas o a diversas épocas. Veamos: avanzado de edad (persona que llega a una edad considerable); la edad del pavo (la adolescencia); del tiempo de Maricastaña (de tiempo muy antiguo); entrado en días (dicho de una persona que se acerca a la vejez); de edad (dicho de una persona muy avanzada en la madurez).

6. Los adjetivos valorativos están presentes en la elaboración de locuciones adjetivales. Ejemplos como: chapado a la antigua (dicho de una persona muy apegada a los hábitos y costumbres de sus mayores); limpio de manos (íntegro, puro); bien hablado (Que habla con propiedad y sabe usar el lenguaje que conviene a su propósito o intento).

7. Y por último, están los adjetivos que funcionan como aptitudes y predisposiciones. Se encuentran ejemplos como: listo de manos (diestro en hurtar o en sacar provecho ilícito de un cargo); pegado a las faldas (hombre que respecto de las mujeres de su familia, se muestra menos independiente de lo que corresponde a su edad); subido de tono (dicho especialmente de una palabra, de una acción, de un chiste, etc. obsceno o impúdico).

En suma, se puede decir que todas las clases de adjetivos calificativos hacen presencia en la construcción de las locuciones adjetivales; aunque unos se encuentren en un número menor, como es el caso de los de color, esto no quiere decir que sean menos importantes en relación, por ejemplo de los de aptitudes.

El segundo apartado del análisis se relaciona con los aspectos gramaticales que intervienen en la creación de las locuciones adjetivales. A partir de las unidades léxicas simples (adjetivos, sustantivos, preposiciones, conjunciones e incluso adverbios), se generan unidades mayores llamadas grupos, frases o sintagmas; dentro de estos están: nominales, preposicionales, verbales adverbiales, conjuntivos y adjetivales, estos últimos objeto de este estudio. Estos grupos sintácticos son estructuras articuladas que se manifiestan en las locuciones, en este el caso, las adjetivales. Es de resaltar que las estructuras presentes se pueden proyectar generando nuevas organizaciones.

Tomemos el modelo Adj. + SP. En primer lugar, está constituido por un núcleo (el adjetivo) y un término (el sintagma preposicional). Ahora apliquemos esto a la locución corto de genio. El núcleo es corto; el término, la preposición de y el sustantivo, genio. En segunda instancia, la locución está constituida por dos sintagmas, el adjetival corto y el preposicional de genio; La proyección sintagmática se puede dar en donde el sintagma adjetival sea corto de, acompañado del sintagma nominal genio. Lo anterior permite apreciar la aparición de una nueva estructura generada de un Adj. + prep. + N, que en términos sintagmáticos corresponde a Adj P. + N (Adjetivo preposicional más nombre). Al respecto, 
es necesario revisar el comportamiento del Nombre en la locución. Es aquí donde se debe tener presente que una de las características fundamentales de las locuciones es su gramaticalidad, pues deben guardar la cohesión representada en la morfosintaxis, la cual no permite la sustitución de un sustantivo por otro; tampoco es posible la supresión de uno elemento, hecho que no sucedió en la aparición de la nueva estructura.

Con base en el ejemplo anterior, se puede comprobar que dicho sustantivo no sufrió alteración; siguió actuando como tal; es decir, conservó sus funciones como ser un atributo o portador de un conjunto de cualidades y complemento del adjetivo. Ahora bien, aquí es necesario decir que la anteposición del adjetivo sobre el sustantivo le permite ser más específico sobre las cualidades del sustantivo. Otras locuciones adjetivales que se ajustan a este tipo de análisis son: blando de corazón, corto de manos, duro de oído, corto de espiritu, entre otras.

La preposición se convierte en eje fundante para la elaboración de las locuciones adjetivales. Las más nombradas en el corpus de locuciones son: $a$, de, sin. Ahora es oportuno ver la incidencia de dichas preposiciones en la construcción de las locuciones adjetivales, no sin antes aclarar que algunas preposiciones tienen contenido léxico (según, bajo, durante, entre); de esta clase no hay evidencias de locuciones en los diccionarios analizados, y la otra clase son las que aportan información únicamente gramatical. Este es el caso que nos compete. Es menester decir que las más relevantes son: $a$ y de, aparecen con menos frecuencia con, hasta y ni. Veamos:

Las preposiciones cumplen dos funciones principales. La primera, sirven de marca para la construcción del complemento del predicado. Tomemos el siguiente ejemplo: Juan estudia a distancia (estudios universitarios o de bachillerato que se realizan por correo 0 a través de los medios de comunicación, sin la asistencia habitual de los alumnos a clase), recogieron la cosecha a brazo (recoger la cosecha de manera manual), lo designaron $a$ dedo (designación arbitraria y autoritaria), él siempre toma los alimentos a la carta (que se sirve según el interesado); y así con otras locuciones como: a mano (dicho de una cosa que pareciendo casual está hecha con estudio), a demonios (dicho de un olor o de un sabor muy malo o desagradable), a metros, a chorro (Chile. dicho de un ladrón que arrebata a la carrera algún bien a alguien), a sangre y fuego (con el máximo rigor matando y destruyendo todo), entre otras.

En segunda instancia, las preposiciones cumplen con el oficio de subordinadores; de esta manera se lleva a cabo el proceso de adjetivación. Veamos: Pedro es de armas tomar (es decidido), es una mujer de bandera (muy bonita, llamativa), el partido estuvo de bigotes (extraordinario), el rector es una persona de hierro (muy firme o inflexible), las vacas de vientre (destinadas para la reproducción) están apartadas. Forman parte de 
este apartado locuciones como: de pueblo (persona rústica), de piedra (insensible), de perros (referido al tiempo, muy malo o desagradable), de libro (perfecto en su línea), entre otras.

Sobre la preposición con puede formar complementos de compañía, colaboración, medio, manera, concesión, el que se hace presente en el corpus de locuciones adjetivales es el de manera. Algunos ejemplos son: Con toda la barba (que está en la plenitud de sus cualidades); con todos los sacramentos (dicho de una cosa que se cumple con todos los requisitos); con gancho (Chile. Dicho de un evento social o de una función que libera de pago al acompañante).

La preposición en se caracteriza por expresar ubicación, en este caso, temporal: en un avemaría (en muy poco tiempo, rápidamente); en días del mundo (nunca); en barbecho (dicho de una tierra labrantía que no está sembrada durante un tiempo para que descanse). También esta preposición manifiesta la naturaleza predicativa para manifestar el estado en que se encuentra algo. Veamos los siguientes ejemplos: La propuesta está en estudio (que está siendo objeto de análisis); el futuro padre está en ascuas (inquieto, sobresaltado); la cosecha aún está en hierba (dicho de los panes o de otras semillas que están aún verdes y tiernos).

La preposición sin expresa privación o carencia; también, alternan con adjetivos y participios. Veamos estos ejemplos: sin segundo (sin par); sin igual (sin par). En este caso, es evidente la existencia de sinonimia entre los sintagmas preposicionales; sin sombra (triste y desasosegado por la falta de algo habitual que se desea o apetece con ansia); sin compromiso (sin novio o novia); sin fisuras (dicho de una actitud, de una idea, etc., consistentes, compactas); sin oficio (ocioso, sin trabajo ni ocupación). El sentido negativo sin explica ciertas equivalencias entre: no + participio: no sombreado, no igualado, no comprometido, no fisurado; a la vez, se puede dar el caso: sin + infinitivo: sin fisurar, sin comprometer, sin igualar, sin sombrear; hecho que genera una lítote, figura retórica que consiste en no expresar todo lo que se quiere dar a entender, pero que deja clara la intención: no sin comprometer; no sin fisurar, no sin igualar.

\section{A manera de reflexión}

En Colombia, los estudios lingüísticos en el campo de la Lexicología, en relación con las unidades sintagmáticas y su grado de fijación son muy pocos. Por tanto, se requiere la influencia y el contagio de investigaciones, relacionadas con obras y artículos de carácter científico, que permitan ver el estudio de la Fraseología como una subdisciplina de la Lexicología. Hecho que, sin lugar a dudas, abrirá nuevos campos de acción mediante una visión clara y pertinente de los tres grandes grupos fraseológicos existentes: colocaciones, locuciones y enunciados fraseológicos, dado que hasta hoy son estudiados indistintamente, llegando, inclusive, a la confusión terminológica

\section{2}


de cada uno de ellos y a denominar locución a aquello que puede ser una colocación y colocación a aquello que quizá sea un enunciado fraseológico.

Lo dicho anteriormente busca concienciar a los estudiosos del lenguaje sobre la necesidad de realizar más estudios fraseológicos relacionados con aspectos relevantes como: definición, delimitación, clarificación de componentes, expresiones y unidades pluriverbales lexicalizadas, expresiones fijas o fraseologismos, discurso repetido, idiomaticidad, fijación, entre muchos aspectos. Lo anterior evidencia que hay varios aspectos que deben ser re-pensados, reformulados, re-planteados; de esta manera, se logrará caracterizar el español hablado, no solo en las comunidades locales, sino también regionales y, por tanto, nacionales. Tarea demasiado ambiciosa por demás, pero que debe ser tomada con responsabilidad, con el objeto de contar con bases sólidas que permitan llegar a un universo lingüístico concreto.

El camino recorrido, al interior de los cinco diccionarios consultados, es una muestra y deseo de profundizar en lo dicho anteriormente. El objetivo fundamental de esta investigación se centró en hacer un estudio comparativo de las locuciones adjetivales que se encuentran en cinco diccionarios de lengua española. El trabajo está constituido por tres grandes momentos. En primer lugar, la elaboración de un corpus lingüístico; así como esbozo teórico en temas relacionados con la Fraseología, el adjetivo y su manifestación en las locuciones adjetivales. Como segundo momento, se hace un estudio que permite evidenciar la existencia de las diferentes clases de locuciones adjetivales que se encuentran en los diccionarios. Parte de este trabajo se recopila en este artículo. Y como tercer aspecto, se está profundizando en la relación lingüística, mediante el nivel gramatical y su incidencia en la construcción de las locuciones adjetivales.

Como reflexión particular, este trabajo investigativo permitió recopilar una muestra significativa de locuciones adjetivales presentes en los cinco diccionarios, objeto de estudio; sin embargo, algunos de ellos no presentan todas las estructuras de las locuciones adjetivales. Ahora bien, lo anterior no quiere decir que de cada caso deba existir una cantidad representativa de muestras, pues esto depende, en gran parte, del tipo de diccionario, el enfoque que se le dé al léxico y la manera como se pone el idioma español en escena o al servicio de la comunidad. Ahora bien, vale la pena revisar nuevas evidencias que quizá cumplan con las características de las locuciones adjetivales, con el fin de incrementar el caudal de locuciones en los diccionarios.

A más de esto, es necesario concluir también que el recurso lingüístico más empleado en estas locuciones son las preposiciones. El caso más relevante es el de la estructura: preposición + el nombre, aquí está el eslabón de las locuciones adjetivales; luego, viene la preposición + el artículo + el nombre, la preposición + nombre + adjetivo y la preposición + adjetivo. Las demás estructuras se toman como casos periféricos; mas no quiere decir esto que sean menos relevantes. 
Las locuciones adjetivales en cinco diccionarios de la lengua española

\section{Referencias bibliográficas}

Baquero Velásquez, J. M. (2010). Lingüística computacional aplicada. Bogotá: Universidad Nacional de Colombia.

Camacho de Báez, B. (2008). Metodología de la investigación científica. Un camino fácil de recorrer para todos. Tunja: universidad Pedagógica y Tecnológica de Colombia.

Carbonero Cano, P. (1978). Criterios para una caracterización funcional de los adverbios. Revista Española de Lingüística. N. 8, fasc. 1, p. 189. Madrid.

Casares, J. (1950). Introducción a la lexicografía moderna. Revista de FILOLOGÍA ESPAÑOLA. ANEJOLII. Madrid, España, p. 167.

Corpas, P. G. (1996). Manual de fraseología española. España: Gredos.

Coseriu, E. (1981). Principios de semántica estructural. (2ª . Ed.). Madrid: Gredos.

Demonte, V. y Bosque, I. (1999). El adjetivo: clases y usos. La posición del adjetivo en el sintagma nominal. En: Gramática Descriptiva de la Lengua Española. Madrid, España: Espasa Calpe.

Diccionario de la Lengua Española (22a . ed.) (2010) (tomos 1 y 2). Novena Tirada, corregida enero de 2009. México: Espasa Calpe.

Diccionario Panhispánico de Dudas (2005). Madrid: Santillana Ediciones Generales.

García-Page M. (2008). Introducción a la fraseología española: estudio de las locuciones. Barcelona: Anthropos.

Gutiérrez Araus, M. L. (1978). Estructuras sintácticas del español actual. Madrid: SGEL.

Lyons, J. (1995). Lenguaje, significado y contexto. Barcelona: Paidós.

Martínez M. J. (1996). Estudios de fraseología española. Málaga: Librería Ágora.

Nueva Gramática de la Lengua Española (2010). Madrid: Espasa Libros

Roca Pons, J. (1970). Introducción a la Gramática. Barcelona: Teide.

Seco, M.; Olimpia, A. y Gabino, R. (2009). Diccionario Fraseológico Documentado del Español Actual. Locuciones y modismos españoles (Vol. 1 y 2). ( $2^{\mathrm{a}}$. Reimp.). Madrid: Aguilar Lexicografía.

Seco, M.; Olimpia, A. y Gabino, R. (1999). Diccionario del Español Actual. (4ª . Reimp.). España: Aguilar Lexicografía.

Varela, F. y Kubarth, H. (1996). Diccionario Fraseológico del Español Moderno. Madrid: Gredos.

Ruiz Gurillo, L. (1997). La fraseología del español coloquial. Barcelona: Ariel.

\section{4}

